\title{
DIOS Y YO: ARGUMENTO CINEMATOGRÁFICO DE GARCÍA MÁRQUEZ SOBRE LA FIGURA DEL DICTADOR LATINOAMERICANO, EPISODIO DE LA NOVELA EL OTOÑO DEL PATRIARCA
}

\author{
POR \\ Alessandro Rocco \\ Università degli Studi di Bari Aldo Moro
}

En varias ocasiones, García Márquez ha fijado en el año 1958 el origen de la idea de una novela sobre la figura de un dictador latinoamericano. Por ejemplo, en "Hoja por hoja, diente por diente", el autor vuelve sobre el tema, aclarando: "La primera versión de El Otoño del patriarca la empecé en Caracas en 1958" (1). Ya en entrevistas anteriores el dato había sido establecido, con añadidura de detalles, como en la larga descripción en El olor de la guayaba:

fue el día en que la Junta de Gobierno estaba reunida en aquel mismo lugar, en Miraflores. Dos o tres días después de la caída de Pérez Jiménez, ¿recuerdas? Algo ocurría, periodistas y fotógrafos esperábamos en la antesala presidencial. Eran cerca de las cuatro de la madrugada, cuando se abrió la puerta y vimos a un oficial, en traje de campaña, caminando de espaldas, con las botas embarradas y una metralleta en la mano. Pasó entre nosotros, los periodistas, caminando de espaldas, todavía. Caminando de espaldas, apuntando con su metralleta, y manchando la alfombra con el barro de sus botas. Bajó las escaleras, tomó un auto que lo llevó al aeropuerto y se fue al exilio. Fue en ese instante, en el instante en que aquel militar salía de un cuarto donde se discutía cómo iba a formarse definitivamente el nuevo gobierno, cuando tuve la intuición del poder, del misterio del poder. (57-58)

El mismo episodio se relata también, por ejemplo, en la entrevista a González Bermejo (15), y en la entrevista a Odete Lara (18), mientras que Vargas Llosa, quien también recuerda el mismo dato (57), sugiere otra interesante hipótesis, a propósito del viaje a Moscú de García Márquez en 1957 y su contemplación del mausoleo de Stalin:

No es imposible que fuera allí, en el marmóreo sótano de la Plaza Roja, contemplando en su urna de vidrio los restos del bigotudo dictador de manos femeninas, que brotara en el espíritu de García Márquez ese demonio que lo llevaría años más tarde a querer escribir una novela sobre un dictador. (56) 
El origen de la idea coincide también con el primer intento de redacción de la novela, que al parecer debe situarse en el mismo año '58, aunque fue una redacción interrumpida rápidamente, pues, como recuerda el autor "no había avanzado mucho en la escritura cuando viajé a La Habana como reportero" ("Hoja por hoja" 1). De otra fase de redacción habla el autor en la entrevista a G. Sheridan y A. Pereira: "yo había trabajado la novela desde mucho tiempo antes. Yo llegué a tener trescientas páginas de $E$ otoño del patriarca aquí en México antes de empezar Cien años de soledad", y también en El olor de la Guayaba, donde añade otros intentos e interrupciones posteriores:

El otoño del patriarca lo suspendí en México, en 1962, cuando llevaba casi trescientas cuartillas, y lo único que se salvó de ellas fue el nombre del personaje. La reanudé en Barcelona en 1968, trabajé mucho durante seis meses, y la volví a suspender porque no estaban muy claros algunos aspectos morales del protagonista, que es un dictador muy viejo. (24)

Acerca de esta redacción mexicana interrumpida en 1962, Dasso Saldívar (429) cita el testimonio de Alvaro Mutis para poner en duda su existencia, pero al parecer, los datos aportados por Gerald Martin (Gabriel García Márquez 323) la confirman. Por lo tanto, desde el surgimiento de la idea general del tema de la novela, hasta la publicación de la misma, transcurren diecisiete años, durante los cuales se dan algunos intentos de redacción abandonados e interrumpidos. Sin embargo, a pesar de la relativa abundancia de informaciones respecto de este dato, no parece haberse mencionado el hecho de que, en un momento de esta trayectoria que va del ' 58 al ' 75 , existió un proyecto para desarrollar el tema del dictador, o de la dictadura, en términos cinematográficos, es decir, orientado a la realización de un film. Proyecto que evidentemente quedó frustrado, y del que sólo se conoce un texto titulado Dios y yo, argumento para el posible desarrollo de un guión cinematográfico sobre el tema. El texto, escrito en colaboración con el guionista y director cinematográfico Luis Alcoriza, fechado a pié de página 1 de noviembre de 1965 , y dado a conocer por Javier Herrera recientemente (Ruiz Mantilla), puede considerarse un ejemplo más de la importancia de un amplio territorio textual poco estudiado pero muy rico en hispanoamérica, constituido por argumentos y guiones cinematográficos de alto nivel e interés literario (Rocco). La lectura de Dios y yo, de hecho, no sólo es útil para el estudio de la escritura fílmica del autor, sino que también puede proporciona información sobre la evolución de su poética con respecto a la elaboración narrativa del tema del dictador. Pues, como afirmaba García Márquez, la primera versión de la novela por él intentada, era "una narración conformista y lineal, en tercera persona" ("Hoja por hoja" 1), o, como explicaba Plinio Apuleyo Mendoza:

Hacía años que trajinaba un primer manuscrito de Elotoño del patriarca sin mayor suerte. Algo no cuajaba en aquel libro. El tratamiento realista de un tema tan desmesurado y ISSN 0034-9631 (Impreso)

Vol, LXXIX, Núms, 244-245, Julio-Diciembre 2013, 863-882 ISSN 2154-4794 (Electrónico) mitológico como el del dictador latinoamericano, lo oprimía oscuramente, castigando su impulso natural hacia la hipérbole, la magnificación de la anécdota y las latentes posibilidades de un estilo que él, temiendo cualquier desenfreno retórico, vivía sujetando por las bridas.

Cuando descubrió que era posible hacer surgir hongos venenosos entre los libros de una biblioteca, que el mar podía ser vendido y su dictador vivir doscientos años, halló la clave de otro libro [...] (110)

El argumento Dios y yo relata un suceso capaz de sintetizar y ejemplificar el tema de la dictadura, en la visión que de ella propone García Márquez: en un país caribeño dominado desde hace treinta años por un dictador ya anciano, medio centenar de niños son secuestrados, luego ocultados y olvidados durante un tiempo en una absurda expedición a las regiones más remotas y salvajes del país, y finalmente eliminados colectivamente, como solución definitiva al problema originado por su secuestro. Como puede verse, se trata de un episodio muy semejante al que la novela relata en la matanza de los niños de la lotería, y que García Márquez refirió con abundancia de detalles en la entrevista a González Bermejo (16). Allí el autor puntualiza que en la novela el episodio sólo ocupa cinco páginas, y que no es en absoluto central, ya que, como dice él mismo, $E l$ otoño del patriarca es un texto que absorbe una gran cantidad de material que podría funcionar por sí mismo, pero que queda reducido a su forma más sintética. La razón de ello es la voluntad de "ir al fondo del asunto" en cada caso, y el episodio de los niños, por ejemplo, no le interesaba en sí, ni por lo ingenioso de la invención del truco para manipular la lotería nacional, sino, básicamente, por la manera de reaccionar del dictador ante la situación.

El desarrollo paralelo de una idea-núcleo en distintos géneros o formatos narrativos, como por ejemplo en forma de cuento, de guión cinematográfico, de nota de prensa, y a veces también de episodio más o menos extenso y detallado de una novela, es usual en la producción literaria de García Márquez. Con respecto al argumento Dios y yo, cabe notar que el tratamiento fílmico del episodio mantiene una relación muy estrecha con la novela en la que se incluye -con importantes variaciones-, pues presenta evidentemente al mismo personaje en el mismo contexto, y se centra en uno de los sucesos que con mayor efectividad pueden expresar la idea general del dictador y de la dictadura latinoamericana. En todo caso, la relación entre el episodio y la novela se plantea en términos de estructura y formato, pues la estructura compositiva de El otoño del patriarca implica la absorción en su flujo narrativo de un sinnúmero de episodios, funcionando por acumulación; mientras que el argumento cinematográfico -y el guión que éste potencialmente sugiere- requieren preferiblemente de una línea de acción única y sintética. De este modo, si la novela es un formato apto para abarcar la historia completa de la dictadura -según el corte y la perspectiva específica que de ella ofrece García Márquez-, el film es más bien adecuado para relatar un evento determinado, pero

Revista Iberoamericana, Vol. LXXIX, Núms. 244-245, Julio-Diciembre 2013, 863-882 ISSN 0034-9631 (Impreso) ISSN 2154-4794 (Electrónico) 
a la vez capaz de ejemplificar y evocar una situación y una temática general. Un ejemplo análogo, tomado de la obra del mismo García Márquez, es el guión cinematográfico escrito para apoyar y celebrar el triunfo de la Revolución Sandinista en Nicaragua, Viva Sandino -también titulado El secuestro-, pues en él, en lugar de tratar de sintetizar la historia de la lucha sandinista desde sus orígenes hasta la toma del poder, se concentra en la acción de un episodio significativo, que evoca sintéticamente el tema general de Sandinismo. De la misma manera, la elección de un episodio excesivo y desmesurado, como la masacre de medio centenar de niños, que incluso presenta resonancias bíblicas, se presenta como la más adecuada para la expresión del tema de la dictadura a través de un relato fílmico, según la concepción desarrollada por García Márquez. Por lo tanto, el tratamiento del tema en el texto Dios y yo puede ser analizado desde una doble perspectiva: por un lado, considerando su carácter de argumento cinematográfico, y por otro, observando la poética narrativa en que se sustenta, es decir, el tipo de relato que el argumento propone.

\section{DIOS Y YO: EL FILM DE LA DICTADURA (O DEL DICTADOR)}

Normalmente, el argumento cinematográfico es un tipo de texto narrativo que relata sucintamente una historia, por lo que el género al que más se acerca es al cuento. Aunque no presenta la estructuración detallada de las secuencias y los diálogos, como el guión, el argumento suele tener ya un esquema preciso de estructura dramática y narrativa de tipo fílmico, es decir, que indica ya, potencialmente, la forma de un film. Así ocurre también con el texto Dios y yo, que se presenta dividido en siete partes, marcadas por asteriscos, que a su vez pueden ser agrupadas en base a una articulación de la historia en tres momentos fundamentales. El primer momento comprende las dos primeras secciones del texto, correspondientes desde el punto de vista funcional a la presentación y al desarrollo inicial de la historia. La representación se mantiene aquí en los límites de la dinámica de una lucha militar, política y mediática, entre una crue dictadura hispanoamericana del siglo veinte y una resistencia interna que encuentra el apoyo de la prensa y de la movilización internacional, en torno a un caso especialmente impactante, como es el secuestro de cincuenta niños por parte del dictador. El segundo momento ocupa la tercera parte del texto marcada por asteriscos, y corresponde al pleno desarrollo del objeto narrativo planteado. Este se basa en una línea de acción que, concentrándose específicamente en la condición de los niños, va creando una situación en la que se mezclan elementos absurdos y de violencia, pues, con el fin de ocultarlos, el dictador manda deportar a los niños secuestrados hacia las regiones más remotas y salvajes del país. La surreal y rocambolesca expedición termina pronto por degenerar en brotes de exasperación, y culmina con la macabra exhibición de una ejecución. Esta enfatiza la bárbara lógica del dictador, que somete a los niños al terrible espectáculo con el objetivo de hacerlos sentir protegidos. El tercer momento de la historia reúne las últimas tres partes del texto, más breves que las anteriores, en función de resolución. La articulación narrativa está orientada aquí a la creación del efecto de mayor impacto posible en el cierre de la narración, cuya terrible culminación presenta la imagen emblemática de la crueldad de la dictadura, y al mismo tiempo la paradójica y atroz actitud del dictador.

Analicemos más detalladamente la construcción narrativa y dramática, a partir de objeto del relato, que, como hemos dicho, es la medida sin precedentes del dictador para doblegar a la resistencia: el secuestro de medio centenar de niños pequeños, hijos de revolucionarios, y la amenaza de degollarlos si sus padres no deponen las armas.

En la primera parte asistimos a un proceso de intensificación de los efectos de esta acción inicial. La situación preliminar de la historia -capital tras una semana de enfrentamientos-, se define a través de una representación realístico-documental del desastre de la guerra y la represión: las ruinas de las barricadas removidas por los militares, "viejos coches incendiados, muebles, sacos de arena", las patrullas que fusilan y torturan a los que no respetan el toque de queda (1). La presentación de la reunión clandestina, significativamente realizada en los sótanos de un barrio apartado, es un contrapunto a la anterior descripción: pero su función principal es la de introducir el objeto del relato -el secuestro de los niños-desde el punto de vista de los rebeldes, a la vez enfatizando su disposición a resistir al más terrible de los chantajes. Esta reacción inesperada, que, como apunta el narrador, deja perplejo al dictador, es la primera de una serie de consecuencias imprevisibles de la acción inicial que constituyen el desarrollo del relato. La irrupción de los soldados, que ejecutan a todos los conspiradores, parece poner fin a cualquier esperanza de la resistencia interna, mostrando una vez más la terrible violencia del régimen; pero también prepara la irrupción de un nuevo actor en la contienda: la información internacional y el movimiento de protesta mundial contra la crueldad del dictador. A continuación, la narración adquiere el ritmo de un rápido montaje de reportajes especiales en la televisión, manifestaciones populares contra las embajadas, sesiones de emergencia en las Naciones Unidas y protestas de madres en las inmediaciones de su sede. Todo ello como un proceso narrativo que desemboca, finalmente, en la representación de la reacción del directo responsable de la situación y protagonista negativo por excelencia, el dictador, que vemos instalado en su enorme y suntuoso palacio colonial, perfecta expresión espacial del poder. Es aquí donde la narración se detiene en las tribulaciones y reflexiones del personaje, insistiendo a la vez en el acoso internacional, gracias al recurso de la lectura en voz alta que su secretario le hace de los telegramas de varios jefes de estado, y hasta del Papa. La angustia y la preocupación del protagonista llegan al extremo de hacerlo sentir al borde del desastre hasta que logra por fin reaccionar, y concentra toda su energía en la inesperada, y aparentemente inverosímil respuesta de negar el secuestro y presentarlo como una 
calumnia de la oposición. La conclusión de la segunda parte, entonces, propone otra vez un rápido ritmo narrativo, pero en el que se muestra ya no el acoso, sino el triunfo del dictador, que con manifestaciones y discursos oficiales, encuentros y declaraciones con diplomáticos complacientes, logra convencer a la prensa y a la opinión internacional, y hasta se da el lujo de proponer una comisión internacional de investigación, que, sin embargo, sólo se anuncia, y no se realiza nunca.

De esta forma, queda clara la lógica de progresión dramática que hace avanzar la narración a través de un crescendo de golpes de efecto capaces de voltear la situación en favor de uno u otro actor de la contienda. La dimensión y el alcance del evento se van ampliando, según avanza el relato, hasta llegar al punto máximo en esta fase: la mistificación y negación de los hechos, que implican el ocultamiento de los niños. El tiempo narrativo se caracteriza por un ritmo acelerado en la cadena de golpes de efecto, aunque se detiene lo suficiente en la explicación y expresión del estado emocional de dictador. El espacio determina también el punto de vista, que se mueve de la visión general de la ciudad, a la guarida clandestina de la resistencia, luego al circuito de la información internacional -con las imágenes de las capitales del mundo y de las N.U.hasta el palacio del dictador; desplazamientos determinados por la necesidad dramática de mostrar las distintas jugadas de los actores en conflicto.

A partir del inicio de la tercera parte, el punto de vista enfoca la situación de los niños, mostrando directamente los sótanos de la vieja fortaleza colonial donde se encuentran recluidos, presentación previa a la decisión de enviarlos hacia las remotas regiones del norte del país. Con la expedición, el registro narrativo del relato sufre un cambio evidente, así como la construcción espacio-temporal del mismo. Pues, como hemos dicho, la solución concebida para ocultar al medio centenar de niños configura una serie de situaciones inusuales y extraordinarias que exceden la dinámica de lucha política-militar y mediática de la primera parte. La primera de estas situaciones tiene que ver con la necesidad de mantener en absoluto secreto la expedición, incluso ante otros militares: así, cuando el comandante de una guarnición cercana a la capital pretende inspeccionar el contenido de los camiones, se llega a rozar un choque armado, mientras los choferes tocan las bocinas a todo volumen para evitar que se escuche el llanto de los niños.

Todo el proceso narrativo de esta parte puede resumirse en el esquema del alejamiento espacio-temporal de la ciudad, entendido como lugar civilizado-a pesar de la dictadura-, hacia regiones de naturaleza salvaje y hostil, en cuyo marco se va dando un insólito proceso de inversión de roles, con un juego de choque semántico de elementos dispares, que, finalmente, se convierte en una creciente exasperación y degeneración, culminante en un macabro estallido de violencia.

El procedimiento de la inversión lógica y funcional atañe en primer lugar al papel de los soldados, cuya ordinaria misión de control se ve aquí convertida en la delicada labor de cuidado de menores: "Al principio los soldados se comportaron como buenas niñeras [...] daban de comer a los menores, los distraían con chupetes, los asistían en sus necesidades y aun les lavaban la ropa mientras estaban acampados a orillas de un río" (10). Paralelamente, los niños mayores empiezan a su vez a identificarse con la expedición y con los secuestradores, convirtiéndose en pequeños soldados que incluso llegan a evitar posibles ataques de la guerrilla: "En realidad, los niños mayores, paulatinamente, iban dejando de ser un problema. Se estaban convirtiendo en soldados" (13).

Nótese también como, siendo en general la expedición un absurdo en sí misma, se enfatiza el choque semántico del lanzamiento de abastecimientos en plena selva, realizado por aviones militares normalmente utilizados contra las guerrillas, posible reminiscencia de las imágenes análogas del film Paisà de Rossellini (1946): “la llegada de los primeros aviones fue una fiesta para los niños. Eran dos viejos aparatos, rezagos de la guerra mundial, que el régimen utilizaba para localizar a los guerrilleros [...] pero esta vez, en vez de bombas, los aviones llevaban provisiones, que arrojaron en pequeños paracaídas en un claro del bosque".

Pero el proceso de inversión más importante es el que afecta la capacidad de resistencia a las dificultades del viaje, pues “al contrario de los niños, que se adaptaban con asombrosa rapidez [...] los adultos empezaron a perder la paciencia" (11). Los soldados, que deberían resistir y soportar el acoso de peligrosos enemigos, son irónicamente aniquilados por las dificultades del cuidado de los niños: "la compasión que algunos de ellos sintieron al principio por los niños se transformó en exasperación" (11).

Toda la construcción narrativa de esta parte del relato está basada, pues, en un mecanismo de creación de situaciones absurdas, pero sometidas a un cambio radical debido al paso del tiempo y al desplazamiento hacia regiones cada vez más hostiles. Al principio, los procedimientos de inversión de lo usual, y de contacto entre elementos distantes y opuestos, generan situaciones sorprendentes, que se mantienen en un tono de humor, a veces negro y surreal. Sin embargo, con el pasar del tiempo y el empeoramiento de las condiciones -adentrándose la expedición en la naturaleza salvaje-, el tono vira hacia la exasperación, culminando con el estallido de violencia, cuando un sargento mayor pierde los estribos y está a punto de matar a golpes a un niño, siendo luego ahorcado, por orden expresa del dictador, ante la vista de los niños. El espectáculo expresa bien la fusión de absurdo y violencia que caracteriza esta parte de la historia, acentuada además por la inesperada reacción de los niños, que asisten al episodio con indiferencia -los mayores como una simple ceremonia más de la disciplina militar, y los menores sin siquiera distraerse de sus juegos. Asociada a la dilatación del tiempo de la historia, que sugiere una suerte de suspensión del mismo, la imagen del ahorcamiento público termina por revelar la verdadera naturaleza cruel y desatinada de la situación, expresión de la perversa lógica del régimen que la ha concebido. Es importante, además, subrayar la ausencia de conclusión del proceso narrativo de esta segunda parte, para el que se 
evoca más bien una indefinida prosecución sin rumbo ni destino: “el viaje proseguiría hasta el fin. Hacia un norte remoto que ahora no parecía ser un punto geográfico, sino un lugar inalcanzable en los confines del olvido" (13)

La tercera y última parte de la historia, que como hemos dicho comprende los últimos tres segmentos del texto, contiene el desenlace del relato, presentando una construcción narrativa destinada a amplificar el impacto dramático de los acontecimientos. Premisa de la resolución es el efecto que la situación de los niños, suspendidos en un olvido forzado, provoca sobre el estado de ánimo del dictador, semejante al de una remoción incompleta. Superada la crisis internacional, aplazada indefinidamente la inspección de una comisión internacional, y recuperado el control sobre el país, el dictador no parece haber recuperado "la paz del corazón". Como soporte de la introspección narrativa en el ánimo del dictador, el relato se vale en este momento de un nuevo personaje, la joven amante que, intuyendo que algo lo inquieta, logra "abrir el polvoriento corazón del anciano" y conocer la verdad. Como en una eficaz sesión de autoconciencia después de confesar sus angustias a la joven concubina, el dictador concibe también la solución del problema, y convoca a un oficial de marina para darle la orden que "había de poner término para siempre a la situación". Opera aquí una importante restricción de la información disponible para el lector-espectador, pues se ignora el contenido de la orden del dictador, y sólo se conoce la que recibe el oficial al mando de la expedición, que ordena dirigirse hacia el mar. El cambio de rumbo en la expedición despierta gran alborozo, con el detalle añadido de que ahora los aviones lanzan cajas de juguetes sobre los niños, y luego la emoción culmina ante la vista del mar. Pero la función de esta aparente evolución positiva de la historia es, gracias al recurso de la restricción de información, provocar en el lector-espectador un sentimiento de suspense e indecisión entre el temor de la catástrofe y la esperanza de una solución positiva para los niños. De esta forma, la alegría de las cajas de juguetes y de la llegada al mar funciona como falso indicio, cuyo efecto dramático principal es amplificar el pathos de la masacre, mostrando la felicidad de los niños precisamente ante su inminente eliminación. Pues la reacción del oficial de la expedición al conocer la orden completa -sin que ésta sea conocida por el lector-espectador tampoco en este momento- induce a confirmar el temor de un final terrible ("Se estremeció, maldijo entre dientes la hora en que su madre lo echó al mundo [...]" (16). Sin embargo, interviene un nuevo procedimiento de retraso de la conclusión final, en la forma de una nueva focalización del estado de ánimo del dictador al recibir por teléfono la noticia de que la orden se está cumpliendo: "una sensación de descanso [...] y una sensación de asco a la vida" que desembocan en la sorprendente decisión de ordenar el fusilamiento de los dos oficiales implicados, pues, como comenta él mismo, "hay ordenes que no pueden cumplirse" (16).

Sólo ahora, finalmente, el relato culmina con la descripción de la ejecución de la orden, que a estas alturas el lector-espectador ha intuido ya, pero que ahora contempla directamente: ISSN 0034-9631 (Impreso)

Vol. LXXIX, Núms. 244-245, Julio-Diciembre 2013, 863-88 ISSN 2154-4794 (Electrónico)
[...] embarcaron a los niños en la barcaza, hacinados como bestias en las oscuras bodegas, y cerraron las escotillas [...] remolcaron la barcaza mar afuera. Allí la embistieron varias veces [...] La desvencijada estructura de madera se hundió al tercer impacto. No se oyó un grito, ni siquiera un lamento: solamente el sordo y desmesurado bramido del agua $[\ldots](17)$

Obsérvese que la construcción temporal y del punto de vista de las secuencias determina la repetición de un mismo suceso desde dos perspectivas: primero la del dictador, y después la de los oficiales que ejecutan el crimen. De esta forma, el dramático final queda indisociablemente ligado a la representación de la mente que lo ha decidido, cuya naturaleza se plasma no sólo en la imagen del terrible delito, sino también en la perversa lógica que, desde su punto de vista, lo ha hecho aparecer como necesario.

El relato termina, luego, con una inversión en la relación de saber entre los personajes y el lector-espectador, ya que muestra a los dos oficiales, de regreso a la costa después de la bárbara operación, enfatizando su ignorancia del destino que los espera, que en cambio el lector-espectador ya conoce: "la orden de fusilamiento -tremenda condecoración por el deber cumplido" (17). Con lo cual se remata la hipócrita paradoja del mandante que venga a sus propias víctimas matando a los ejecutores materiales de su orden, con ello expulsando de sí mismo la culpa y la responsabilidad de sus actos, además de eliminar a los únicos testigos del crimen.

En resumen, se observa que el argumento presenta una articulación en tres partes, que supone también la alternancia o la sucesión de distintas modalidades o registros narrativos en el tratamiento del objeto central del relato. La primera parte muestra un tratamiento realista, propio de un film político documental, en el que se focaliza también el alcance y la importancia, en los conflictos políticos del siglo xx, de la manipulación de la información. La segunda, centrándose en la expedición de los niños, apunta una suerte de relato insólito y extraordinario, con la serie de eventos ya mencionados. Vista en el conjunto de la construcción dramática del argumento, toda esta exasperante operación de absurdo y cruel ocultamiento funciona como procedimiento de creación e intensificación de los términos contradictorios de un dilema, ya que, en efecto, muestra cómo la voluntad del dictador de preservar a los niños manteniendo el secreto de su secuestro se convierte cada vez más en una misión imposible. Por lo tanto, la focalización directa del punto de vista del dictador -la expresión y explicación de sus reflexiones y sentimientos con respecto al objeto del relato-, que conforma la modalidad narrativa principal de la tercera parte, se percibe como la consecuencia natural de la situación anterior, acentuando la contradicción fundamental o el desdoblamiento absurdo de la lógica del dictador, que, incapaz de deshacerse de la preocupación por la suerte de los niños, logra al final encontrar la fuerza y la determinación, expresadas por supuesto desde una distancia fundamentalmente irónica, para deshacerse de los niños.

Revista Iberoamericana, Vol. LXXIX, Núms. 244-245, Julio-Diciembre 2013, 863-882 ISSN 0034-9631 (Impreso) ISSN 2154-4794 (Electrónico) 
Queda claro, entonces, que toda la construcción final del relato apunta a enfatizar la imagen de la crueldad y cinismo de la dictadura, capaz de los más atroces delitos, basándose en una suerte de estudio psicológico de la figura del dictador, que bien queda definido, a nuestro juicio, en las observaciones de Canfield:

Uno de los arquetipos más veces configurado en la literatura hispanoamericana [...] es el arquetipo del dictador, que no es otra cosa que la versión degradada de la figura heroica del padre-rey. Es decir, que aquél en quien el hijo-pueblo había puesto todas sus esperanzas ha traicionado esas esperanzas, revelándose padre despótico, héroe malvado y gobernante tirano. ("Dos enfoques" 965)

Es precisamente en El otoño del patriarca donde "con mayor nitidez confluyen en la figura del déspota los roles contradictorios del padre protector y destructor" (965), tratándose, añade Canfield, de la "literarización de un arquetipo que se ha ido configurando como la estructuración literaria personal de un tema simbólico del inconsciente colectivo de los pueblos hispanoamericanos" (El "Patriarca" 119).

De hecho, la resolución no propone la imagen de la masacre exclusivamente como horrendo delito, sino que le antepone su siniestra preparación y motivación en la mente del dictador, para quien la decisión es percibida, paradójicamente, como sacrificio y sufrimiento. Lo que parece ponerse en juego, entonces, es el papel simbólico del dictador como padre, pues es sobre el filo de esta ambigüedad, de la distancia irónica con que se muestra la degradación de tal papel simbólico, que se realiza el efecto final del texto, y se explica también la asunción, en forma de trágica farsa, del rol de protector de los niños, y del mecanismo para descargarse definitivamente la conciencia.

Todo esto da como resultado un registro narrativo bastante complejo en el que, al nivel de la representación de una simple y llana barbarie y atrocidad humana y política, se añade la focalización del estado de ánimo y de las reflexiones psicológicas de un dictador criminal; es decir, que se presenta la auto-justificación del personaje de sus propios crímenes. Es evidente que en el argumento Dios y yo el narrador mantiene una distancia irónica, un negro y tácito sarcasmo con respecto a dichas reflexiones, y sin embargo hay que reconocer que el efecto dramático de la conclusión depende, en gran medida, precisamente de que durante cierto tiempo se asume como operante el límite moral, la prohibición de maltratar a los niños inocentes, también para el dictador, por lo que el crimen mayor es su mezquina e hipócrita manera de transgredir ese límite. Por lo tanto, podría decirse que en este texto ya está indicada y trazada una dirección que se profundiza en El otoño del patriarca: la asunción del punto de vista del dictador, ya no sólo con una clara indignación irónica o sarcástica, sino con cierto grado -variable según los casos y los momentos- de identificación efectiva. ISSN 0034-9631 (Impreso)

Vol, LXXIX, Núms. 244-245, Julio-Diciembre 2013, 863-882 ISSN 2154-4794 (Electrónico)
DIOS Y YO EN RELACIÓN CON EL OTOÑO DEL PATRIARCA

En el argumento se presentan varios elementos que caracterizan también al personaje y la ambientación de la novela. En primer lugar, podríamos subrayar la importancia en la novela de la representación espacial y de los ambientes, sobre todo de la casa presidencial, como subrayan Onstine (428) y López (68), pero también la distinción entre la ciudad y lo que queda fuera de ella (López 67), elementos que en el argumento quedan también parcialmente establecidos, siendo fundamental en la narración fílmica la inmediatez significante de lugares y escenografías. Detalles y situaciones esbozadas en el argumento son familiares en la novela: por las calles de la ciudad todavía parecen resonar las "carrozas de los virreyes". La situación que ejemplifica la manifestación del poder arbitrario del dictador es la parálisis del tráfico de la ciudad para permitirle desplazarse por la avenida desierta rumbo a la casa de su concubina de turno, que además es una joven casi adolescente. También hay descripciones del personaje que reaparecen en la novela, como cuando es definido un anciano capaz de "adelantarse a las segundas y hasta las terceras intenciones de sus interlocutores". Pero más allá de estos detalles, nos centraremos en el significado estructural del episodio.

Partiremos de la constatación de que en la novela la intención del autor es "atacar el abuso extremo del poder del dictador, y al mismo tiempo, presentar su trágico sufrimiento psicológico" (Ugalde 11). Es por ello que sobre la novela se han expresado comentarios tan diferentes, como el de Oscar Collazos, quien después de proponer su personal resumen de la narración concluye que "en gran medida, El otoño del patriarca es una sátira" (204); y el de Carmen Martín Gaite, quien afirma en cambio que se trata de una "novela psicológica" (213). Para Ugalde, ambas observaciones son acertadas, pues el tratamiento irónico le permite al autor encontrar un punto de equilibrio entre los polos opuestos de la denuncia y de la identificación (11). Como recuerda Gerald Martin, en todo caso, la novela ha provocado toda clase de reacciones, incluso comentarios decididamente hostiles (Gabriel García Márquez 429), en muchas ocasiones debido a que los críticos -entre ellos el mismo Martin ("Yo el supremo" 73) - "tendían a sentirse ultrajados porque hubiera trazado un retrato moderadamente compasivo" del dictador (Gabriel García Márquez 411).

En efecto, el mismo García Márquez subrayó en una entrevista a G. Sheridan y A. Pereira que uno de los aspectos que le interesaban más en la novela era superar una visión maniquea de la realidad histórica, y presentar la parte de víctima que también suelen tener los dictadores, enfocando además directamente su perspectiva interior, narrar su historia "desde adentro"; aunque, como demuestra Ezquerro, el punto de vista es en sí "próximo al del protagonista" pero a la vez "lo desborda apoyándose constantemente en relatos ajenos [...] en el discurso múltiple de los personajes de la ficción" (242).

Con respecto a lo dicho, es de notar que en el argumento que aquí analizamos, el personaje del dictador ocupa una posición central en la dinámica narrativa y dramática,

Revista Iberoamericana, Vol. LXXIX, Núms. 244-245, Julio-Diciembre 2013, 863-882 ISSN 0034-9631 (Impreso) $\quad$ ISSN 2154-4794 (Electrónico) 
por lo que, en cierta medida, se cumple lo que García Márquez expresa en la entrevista con González Bermejo, donde revela que le interesaba específicamente la reacción del dictador ante los hechos (16). El argumento, entonces, propone un film sobre la dictadura que en realidad es más bien un film sobre el dictador.

Aunque al principio se enfatiza principalmente la situación de guerra y la presencia de una resistencia interna, tenemos ya dos elementos de introspección del personaje del dictador cuando se indica que se encuentra en "estado de excitación paranoica" (1) por las actividades de la resistencia, y cuando se señala brevemente su perplejidad ante la negativa a rendirse de los revolucionarios, aun frente a la amenaza de muerte para sus hijos (3). Pero es después de la descripción del escándalo internacional cuando realmente entramos en el vivo de la introspección del dictador, presentado en su palacio presidencial, y caracterizado en base a categorías psicológicas y de estado anímico, como por ejemplo al notar que "en otras circunstancias la emoción de sentirse convertido en el centro del universo habría apenas colmado sus delirios de grandeza" (5). También tenemos un esbozo de mitificación de su figura, que se da precisamente a partir de la perspectiva narrativa interna al personaje, quien en su "febril imaginación" concibe su régimen como "un reino sin límites que había de perdurar hasta el fin de los siglos" (5). Es de notar, al respecto, que lo que en el argumento de 1965 se menciona como un aspecto propio de la visión del personaje, se convierte más adelante en un elemento estructural de la estética de García Márquez al abordar la novela, pues como declara, en cierto momento se dio cuenta de que lo que más podía interesarle era plantear la historia de un dictador que no vive sólo 82 años, sino 270 (Lara 21), y que por lo tanto refleja al único personaje mítico creado en la historia latinoamericana, que es precisamente el dictador, que también es "el gran criminal" (Sheridan y Pereira). Por lo tanto, si, como sabemos, el planteamiento de los primeros intentos por escribir la novela del dictador era de tipo realista, en el argumento tenemos claramente un primer esbozo, en estado embrionario, de evolución hacia una poética narrativa nueva.

Pero más evidente, sin duda, es el planteamiento de la perspectiva narrativa interna que continúa y se profundiza cuando el texto da cuenta de la inquietud del protagonista por la situación de los niños: "la paz en el corazón del dictador era tan aparente como en las calles" (13-14). Como ya se ha dicho, la presencia de la concubina que se propone averiguar qué es lo que inquieta al dictador, se entiende como un recurso de dramatización escénica de la introspección, que se establece en forma de un potencial diálogo entre los amantes, y que el texto del argumento resume de esta forma:

[...] el dictador no tenía un minuto de paz, atormentado por la situación de los niños. Cuando ordenó llevarlos al norte, había cedido a un impulso primario: era una región casi desierta donde nadie podía encontrarlos. Ahora el peligro había pasado, y no sabía qué hacer, por más que se exprimía la imaginación. Por una parte, los niños no debían ser vistos. Por otra, no podían continuar indefinidamente en la selva, sometidos a un

Revista Iberoamericana, Vol. LXXIX, Núms. 244-245, Julio-Diciembre 2013, 863-882 ISSN 0034-9631 (Impreso) ISSN 2154-4794 (Electrónico) régimen despiadado. Era un callejon sin salida. Y mientras tanto, el, padre y protector de la nación por la gracia de Dios, sucumbía al insoportable tormento de aquella tremenda alternativa. No: era una situación injusta, inmerecida, tanto para el medio centenar de criaturas errantes, como para él mismo. (14)

En el argumento, el desahogo con la concubina pone fin al tormento del dictador, pues le inspira la calma para la decisión, que el lector-espectador conocerá sólo más adelante, no sin antes asistir a la reacción del personaje ante los hechos, que el texto describe con estas palabras: "Experimentó una sensación indefinible. Era, almismo tiempo, una sensación de descanso por haberse quitado de la conciencia un peso insostenible, y una sensación de asco a la vida por el precio que había puesto a su tranquilidad" (16)

Podemos evidentemente poner en duda la posibilidad misma de una actitud no irónica o sarcástica frente al tormento de verse obligado a matar a tantos niños, pero la cuestión de la visión del dictador como víctima en el caso de la novela El otoño del patriarca, y en general de la visión de García Márquez del poder, debe tomarse en serio. Probablemente, el recurso de la ironía no sea suficiente para explicarla, ni para resolver de una vez por todas el problema de un equilibrio aparentemente imposible entre la representación de los horrores cometidos por el dictador, y la expresión de lo sufrido por el mismo. Una clave sobre el asunto la da el mismo autor, cuando afirma que "las biografías y los anecdotarios de los dictadores demuestran que siempre tienen algo de víctimas, y, eso sí, los de todos los tiempos, de Creonte para acá” (Sheridan y Pereira).

La referencia a Creonte llama la atención, y nos sugiere verificar el tratamiento que le reserva García Márquez al personaje en su personal reescritura del Edipo Rey, realizada en forma de guión cinematográfico junto con el director colombiano Jorge Alí Triana, para la película Edipo Alcalde (1996). Aquí, hacia el final del film, el Alcalde, que ya ha descubierto su propia identidad, se dirige a Creonte con estas palabras:

El círculo se ha cerrado. Ahora eres dueño del poder que todo lo puede. Tienes a asesino de Layo. Tienes sus culpas purificadas por tu sangre y la mía, y por la de los muertos incontables de esta tierra de desgracias. Tienes las llaves que todo lo abren y todo lo cierran. Lo mismo las puertas de la guerra que de la paz. ¡Es tu castigo! (124; énfasis mío)

El castigo, entonces, parece ser el poder mismo, presentado como la condena del hombre, como también afirma el narrador al final de Elotoño del patriarca, cuando define al dictador una víctima del "culto abrasador del vicio solitario del poder", concluyendo luego que se trata de "un vicio sin término cuya saciedad generaba su propio apetito hasta el fin de todos los tiempos" (269-270). Más adelante, en evidente relación con la revelación de la verdadera naturaleza del poder, la novela de García Márquez evoca la cuestión de la identidad, cuando el narrador recuerda que "nosotros sabíamos quienes

Revista Iberoamericana, Vol. LXXIX, Núms. 244-245, Julio-Diciembre 2013, 863-882 ISSN 0034-9631 (Impreso) ISSN 2154-4794 (Electrónico) 
éramos mientras él se quedó sin saberlo para siempre" (271). El tema de la identidad, elemento central en la tragedia de Sófocles, cuyos vínculos con El otoño del patriarca han sido analizados en detalle por Camacho Delgado (24-32), se relaciona también con la problemática de la verdad. En efecto, si, como se afirma en la novela, para el dictador la mentira había resultado "más cómoda que la duda, más útil que el amor, más perdurable que la verdad" (270), se debe notar que esto es precisamente lo que e personaje de Edipo jamás podría aceptar, pues su principal objetivo en el drama es la búsqueda de la verdad. Esta, sin embargo, no se reduciría simplemente al descubrimiento de su verdadera identidad en el sentido de filiación y parentesco, sino más generalmente se referiría también a la verdadera naturaleza y condición del hombre con respecto a poder: condenado a sucumbir ante el deseo del poder, a terminar devorado por el poder, y finalmente, como señala Palencia-Roth (1016), destinado a perderse en el olvido. Pensamos, entonces, que por lo menos una parte de ese complejo significado político de la novela que el autor declaró en cierto momento no estar dispuesto a explicar (Sheridan y Pereira), podría ser precisamente una reflexión sobre el poder, en sí mismo, como la raíz del mal del hombre, tanto a nivel individual como a nivel de la sociedad, sin que ello implique, sin embargo, la victimización y justificación histórica de los dictadores. Como observa Sierra, en la novela de García Márquez el poder es algo que afecta e involucra a todos, es decir, que el problema del poder es un problema del hombre como tal:

La virtud indeleble de esta novela de tiranos es hacernos sentir a la vez opresor y oprimido, mostrarnos que el monstruo se construye con retazos de nuestro discurso, de nuestras leyendas populares, de nuestros deseos de progreso y de nuestros sueños más íntimos -y advertirnos que, para liberarnos de su reaparición, deberemos vigilarnos a nosotros. (119)

Aunque, según Ortega, también se da la posibilidad de una relación distinta frente al poder, de una resistencia que en la novela se expresa en las "páginas finales con el aliento casi épico con que la escritura elabora el nacimiento de la conciencia" (438): el surgimiento de una conciencia fundadora y comunitaria sustentada en la cultura popular, que es "existencia real frente al poder" usurpador

En todo caso, es un hecho que en El otoño del patriarca el dictador no padece sólo irónicamente o grotescamente, como en Dios y yo, sino que sufre literalmente, por muchas razones y en diversas circunstancias. Pero, ¿qué ocurre con el episodio de los niños? ¿Cómo puede, incluso en la perspectiva ahora esbozada, representarse seriamente la decisión de matar a tantos niños como tormento?

En efecto, el episodio nunca ha sido considerado un posible ejemplo de identificación con el protagonista, ni mucho menos de expresión de su estado de sufrimiento, como lo han sido otros episodios y situaciones de la novela. En general, siempre ha sido visto como una de las manifestaciones más claras de su violencia brutal. Sólo para poner algunos ejemplos, pueden verse las menciones al episodio en Palau De Nemes (181), Luna (29), Tobin (69), López Alvarado (40), De Castro Korgi (36). Navajas (209) lo ve como evento apocalíptico (209), Camargo Rojas y Polo García como paradójica expresión de valor (103), mientras que Zamora subraya la manipulación de la realidad y la negación de la existencia de los niños (352).

El mismo García Márquez contó el episodio antes de la publicación de la novela sin mencionar el anterior tratamiento fílmico, en la entrevista a González Bermejo (16) respondiendo a la pregunta sobre qué había escrito ese día. La versión que el autor relata aquí es parcialmente distinta a la que finalmente quedará en la versión definitiva de la novela, pero ya es casi el mismo episodio, pues ha adquirido todos aquellos rasgos que lo diferencian del argumento Dios y yo. En primer lugar, la razón del secuestro de los niños, que nada tiene que ver con la guerra interna, sino con un truco para ganarse la lotería. En segundo lugar, que el dictador no es el que decide el secuestro, sino que se entera en cierto momento que los servicios de seguridad han decidido no soltar a los niños para que no revelen el truco de la lotería. En tercer lugar, el número de los niños, que aquí son dos mil y no cincuenta. Luego tenemos las diferencias con respecto a la versión de la novela, pues en la entrevista García Márquez explica que hay un personaje que le vende el sistema de la lotería al dictador, y que luego involucra a todo el Estado Mayor en las ganancias, lo que explica el secuestro de los niños. Además, otro detalle importante es que el dictador, presa de la duda y la preocupación sobre la situación de los niños, se desahoga con la madre (y no con la amante, como en el argumento), y es ella quien le abre los ojos diciéndole que no tiene más remedio que matarlos, porque igualmente se morirían en la guerra. Es evidente, entonces, que García Márquez todavía no resolvía completamente ciertos detalles del episodio al contarlos en la entrevista, pero sí tenía ya claros tres elementos de principal importancia: aumentar considerablemente el número de los niños, eliminar el contexto de lucha política en que se da el secuestro, sustituyéndolo con un contexto más ingenioso, y sobre todo, a nuestro modo de ver, restarle responsabilidad al dictador en el origen del problema. No necesariamente esto se debe a una intención de matizar la culpa del dictador para problematizar más su tormento, pues también se inscribe en la serie de casos y situaciones que describen las limitaciones del poder del dictador con respecto a otros actores. Sin embargo, también tiene algo que ver con ello, pues en la novela se enfatiza precisamente que, sin ser responsable directo de la situación, el dictador se encuentra solo frente a la necesidad de solucionarla. Una vez más, entonces, incluso en este episodio, se hace referencia a la "soledad del poder". Además, hay otro aspecto: en el argumento la presencia y la actuación de la joven amante puede funcionar como elemento que acentúa lo irónico y grotesco de la actitud del dictador. En el relato de la entrevista, el papel de la madre insiste en subrayar el elemento edípico del carácter del dictador, también muchas veces observado. Pero en la novela, el intento de remover de su conciencia la situación de los
Revista Iberoamericana, Vol. LXXIX, Núms. 244-245, Julio-Diciembre 2013, 863-882 ISSN 0034-9631 (Impreso) 
niños queda asociado, entre otras cosas, a un acto sexual, materia en que, a lo largo de toda la narración, el personaje es tratado y presentado, -como subraya Menton (198 199)-, de manera evidentemente patética. He aquí el pasaje de la novela:

Cuando entró una mulata de servicio a recoger los huevos, sintió la resolana de su edad, el rumor de su corpiño, se le echó encima [...] la tumbó de un zarpazo sin desvestirla ni desvestirse $[\ldots]$ resbaló, se despeñó en el vértigo ilusorio de un precipicio surcado por franjas lívidas de evasión y efluvios de sudor y suspiros de mujer brava y engañosas amenazas de olvido [...] pero en el fondo del precipicio estaban otra vez los rastrojo cagados, el sueño insomne de las gallinas, la aflicción de la mulata [...] y él rezongó tratando de domar la rabia de otro amor sin amor. (114-115; énfasis mío)

Luego, el tormento por la situación de los niños vuelve a aflorar en la conciencia del dictador en la forma de voces nocturnas que el viento hace penetrar por la ventana de su cuarto; lo que enfatiza la insistencia en la introspección psicológica, pero ya no de manera simplemente irónica o grotesca, sino realmente como la dramatización fantástica de una batalla contra sus fantasmas, cuyo valor psicológico-simbólico es mucho más perceptible que en el argumento o en el breve resumen de la entrevista. En la novela, el dictador despierta de golpe por la presencia de las voces de los niños cantando, y grita "ya no más, carajo, o ellos o yo", lo que evidentemente no sólo explica que el tormento por la situación concreta de los niños ha llegado a culminación, sino que también evoca claramente la contienda simbólica entre el padre y los hijos, con una serie de posibles asociaciones como el mito de Cronos, o también, como apunta Díaz Arenas, con el episodio de "La matanza de los inocentes" del Nuevo Testamento (El realismo mágico 71-72), expresiones del miedo al paso del tiempo, al futuro y a la suplantación generacional. Así el texto de la novela:

[...] mientras exprimía su orina exigua acariciaba al niño inclemente del testículo herniado hasta que se le enderezó la torcedura, se le durmió en la mano, cesó el dolor, pero volvió al instante con un relámpago de pánico cuando entró por la ventana el ramalazo de un viento de más allá de los confines de los desiertos de salitre y esparció en el dormitorio el aserrín de una canción de muchedumbres tiernas [...] y era un coro de voces tan numerosas y distantes que él se hubiera dormido con la ilusión de que estaban cantando las estrellas, pero se incorporó iracundo, ya no más, carajo, gritó, o ellos o yo, gritó, y fueron ellos [...] (115)

Puede notarse la semejanza con el momento de la visita de la muerte, que también irrumpe de noche en su dormitorio: "se tiró bocabajo [...] y se durmió en el acto, pero a las dos y diez despertó con la mente varada y con la ropa embebida en un sudor pálido [...] estremecido por la certidumbre de que alguien lo había llamado en el sueño [...] y entonces la vio, era la muerte" (268). Además, la canción infantil que García Márquez

Revista Iberoamericana, Vol. LXXIX, Núms. 244-245, Julio-Diciembre 2013, 863-882 ISSN 0034-9631 (Impreso) ISSN 2154-4794 (Electrónico) inserta en el pasaje de los niños, hace directa referencia a la muerte, tratándose de fragmentos de Mambrú se fue a la guerra ("que mambrú se ha muerto / lo llevan a enterrar/ en caja de terciopelo"), canción muy popular en España y Francia(DíazArenas, Folklore Iberoamericano 97), a la que se suma la cita de dos verso de "Sonatina", de Rubén Darío: "el feliz caballero que te adora sin verte / y que llega de lejos, vencedor de la muerte" (Díaz Arenas, El realismo mágico 18).

De esta forma, no sólo tenemos un más alto y complejo nivel de introspección en el episodio de la novela con respecto al del argumento, coherente además con el tratamiento no maniqueo de la figura del dictador, sino que también tenemos una más clara evocación del valor mítico-simbólico del episodio, coherente con la evolución de la estética del autor hacia la incorporación del mito en su narrativa. Para entender el alcance de dicho significado mítico y simbólico del episodio en la novela, podemos acudir a las reflexiones de Canfield, que explican el sentido profundo del conflicto simbólico padre-hijos, subyacente al conflicto pueblo-dictador:

Entre los muchos elementos sorprendentes de esta novela, uno de los más inesperados es el cambio de perspectiva narrativa que ocupa las últimas páginas, después de la muerte del protagonista. El lector siente a la vez desconcierto y regocijo: la voz narrante es la del pueblo, pero por primera vez no se trata de una conciencia sometida, confundida o insegura, sino de una conciencia lúcida que ve al dictador como un enemigo vencido y comprende por qué ha podido vencerlo. [...]

No es casual que solo al final de la novela el lector venga a leer un juicio semejante. El autor lo ha inducido sutilmente, a lo largo de la narración, a reconocer lo que de sí mismo había en el padre-tirano y, por tanto, a reconciliarse con la parte oscura de sí, hasta ahora proyectada en el otro; después de lo cual se puede separar al tirano de su valor simbólico de padre y se puede enjuiciarlo, con firmeza y sin odio, para abrir desde ahora el camino a la reconstrucción o, dicho sea en término mítico-analítico, al "renacimiento". En este sentido, la lectura, aun mas que la escritura de El otoño del patriarca es verdaderamente catártica. Piedad y terror por la "bestia solitaria", y a fin el juicio sereno de quien, volviendo la tremenda página, puede empezar de nuevo. ("Dos enfoques" 975)

Por lo tanto, el conflicto padre-hijos se comprende en toda su dimensión y alcance simbólico, del cual el episodio de la masacre de los niños viene a representar tal vez la expresión más explícita y directa, pues es donde más claramente el papel de padre protector degenera en el de padre devorador de sus hijos. Además, es preciso notar que, en el argumento Dios y yo, el terrible valor simbólico-político de la matanza de los "hijos de los revolucionarios", adquiere también el inquietante carácter de anticipación de la criminal sustracción de los hijos de los desaparecidos en Argentina por parte de los militares, en el marco de un genocidio con base ideológica. Lo que induce a suponer que García Márquez, recordando muchos años más tarde su trabajo de guionista con

Revista Iberoamericana, Vol. LXXIX, Núms. 244-245, Julio-Diciembre 2013, 863-882 ISSN 0034-9631 ISSN 2154-4794 (Electrónico) 
Luis Alcoriza en México en los años sesenta, se refiriera especialmente a este texto -aunque no lo mencionara-, al afirmar que: "Nuestro sueño era reflejar sin tapujos el horror del mundo que estábamos viviendo. Pero no recuerdo que hubiéramos concebido tres o cuatro episodios terribles cuando la realidad nos aventaba por otros desfiladeros más sangrientos", por lo que, cada vez era más "desmesurada nuestra desazón por e mal estado del mundo y el oscuro destino de la humanidad" ("Un buen recuerdo de mi mejor amigo" 146).

En conclusión, el argumento Dios y yo, primer paso para el completo desarrollo fílmico de la idea base que podríamos definir "episodio de los niños", muestra la importancia del trabajo para el cine de García Márquez en el ámbito de su obra narrativa entendida como un todo orgánico. Pues, se trata de un proyecto para un film político, pero con resonancias simbólicas, sobre un tema central del imaginario literario de autor, desmintiendo la idea de que el trabajo para el cine haya ocupado una posición marginal o periférica con respecto a sus obsesiones principales. Además, en él pueden verse, en estadio de esbozo, pero con toda claridad, algunos elementos fundamentales de la evolución poética que llevó la idea germen de la novela del dictador, concebida probablemente en el año 1958, a su forma definitiva en 1975

\section{OBRAS CONSULTADAS}

Camacho Delgado, José Manuel. Magia y desencanto en la narrativa Colombiana. Alicante: Universidad de Alicante, 2006. 21-40.

Camargo Rojas, Ciro Antonio y Polo García, Victorino. "Literatura y mito. El otoño del patriarca a la sombra de Cervantes". Anales de la Universidad de Murcia 43/1-2 (1985): 79-109.

Canfield, Martha. El "Patriarca" de García Márquez: arquetipo literario del dictador hispano-americano. Firenze: Opus Libri, 1984.

"Dos enfoques de Pedro Páramo". Revista Iberoamericana 148-149 (1989): 965-988.

Collazos, Oscar. García Márquez, la soledad y la gloria: su vida y su obra. Barcelona: Plaza y Janés, 1983

De Castro Korgi, Martha Sylvia. "Testimonio de un despojo". Desde el jardín de Freud 3 (2003): 32-47.

Díaz Arenas, Angel. El realismo mágico en El otoño del patriarca de Gabriel García Márquez: claves para una lectura codificada. Bonn: Romanistischer Verlag, 1987. Folklore iberoamericano en El otoño del patriarca de Gabriel García Márquez. letras, partituras, y estudio histórico-comparativo. Bonn: Romanistischer Verlag, 1988.

Earle, Peter, ed. Gabriel García Márquez, el escritor y la crítica. Madrid: Taurus, 1981
Ezquerro, Milagros. "Función narradora e ideología en El otoño del patriarca". Gabriel García Márquez. La modernidad de un clásico. José Manuel Camacho Delgado y Fernando Díaz Ruiz, coords. Madrid: Verbum, 2009. 238-243.

García Márquez, Gabriel y Alcoriza, Luis. Dios y yo (argumento inédito). Filmoteca de Madrid, 1965.

El otoño del patriarca. Barcelona: Plaza y Janés, 1975.

Viva Sandino. Managua: Editorial Nueva Nicaragua, 1982

El asalto, operativo con que el FSLN se lanzó al mundo. Managua: Editorial Nueva Nicaragua, 1983.

El secuestro. Managua-Salamanca: Editorial Nueva Nicaragua-Lóguez, 1983. El olor de la guayaba: conversaciones con Plinio Apuleyo Mendoza. Buenos Aires: Sudamericana, $1993^{3}$.

Edipo Alcalde (guión inédito). Filmoteca de Madrid, 1992.

"Hoja por hoja y diente por diente". Sololiteratura. Literatura Hispanoamericana. $<$ http://sololiteratura.com/ggm/marquezhoja.html>. 4 abr. 2012.

"Un buen recuerdo de un mejor amigo". Luis Alcoriza, Soy un solitario que escribe. Manuel González Casanova. Badajoz: Festival Ibérico de Cine, 2006. 145-147.

Gil López, Ernesto J. "El espacio en El otoño del patriarca de Gabriel García Márquez". Revista de filología de la Universidad de La Laguna 2 (1983): 65-70.

González Bermejo, Ernesto. "García Márquez: ahora doscientos años de soledad". Triunfo XXV/ 441 (1970): 12-18.

Herrera, Javier. “Dos argumentos cinematográficos inéditos de Gabriel Garcia Marquez: una comedia romántica y una prefiguración de el otoño del patriarca". Hispanic Research Journal: forthcoming.

Lara, Odete. “García Márquez”. El escarabajo de oro 47 (1973-1974): 18-21.

López Alvarado, Douglas Augusto. "Mito, culto y represión en El otoño del patriarca". Cuestiones Políticas 26/44 (2010): 34-54.

Luna, Norman. "The Barbaric Dictator and the Enlightened Tyrant in Elotoño del patriarca and El recurso del método". Latin American Literary Review 8/15 (1979): 25-32.

Martín Gaite, Carmen. "El otoño del patriarca o la identidad irrecuperable". Gabriel García Márquez, el escritor y la crítica. Peter Earle, ed. Madrid: Taurus, 1981. 210-213.

Martin, Gerald. "Yo el Supremo: The Dictator and his Script". Forum for Modern Language Studies 15/2 (1979): 169-83. Gabriel García Márquez, una vida. Barcelona: Mondadori, 2009.

Mendoza, Plinio Apuleyo. La llama y el hielo. Bogotá: Planeta, 1984.

Menton, Seymour. "Ver para no creer: El otoño del patriarca". Gabriel García Márquez, el escritor y la crítica. Peter Earle, editor. Madrid: Taurus, 1981. 189-209.
Revista Iberoamericana, Vol. LXXIX, Núms. 244-245, Julio-Diciembre 2013, 863-882 ISSN 0034-9631 (Impreso)
Revista Iberoamericana, Vol. LXXIX, Núms. 244-245, Julio-Diciembre 2013, 863-882 ISSN 0034-9631 (Impreso) ISSN 2154-4794 (Electrónico) 
Navajas, Gonzalo. "Historia circular y nueva temporalidad en El otoño del patriarca de Gabriel García Márquez”. Anales de Literatura Hispanoamericana 16 (1987): 205-214.

Onstine, Roberto. "Forma, sentido e interpretación del espacio imaginario en El otoño del patriarca". Cuadernos Hispanoamericanos 317 (1976): 428- 433.

Ortega, Julio. "El otoño del patriarca: texto y cultura". Hispanic Review 4 (1978): 421-446.

Palau de Nemes, Graciela. "El otoño del patriarca". Hispamérica: Revista de Literatura 11-12 (1975): 173-183.

Palencia-Roth, Michael. "El círculo hermeneutico en El otoño del patriarca". Revista Iberoamericana L/128-129 (1984): 999-1016.

Rocco, Alessandro. La scrittura immaginifica: il film scritto nella narrativa ispanoamericana del novecento. Roma: Aracne, 2009.

Ruiz Mantilla, Jesús. “Dios y yo, el otro film desconocido”. El País. 30 Nov. 2011.<http:// elpais.com/diario/2011/10/30/cultura/1319925602_850215.html>. 4 abr. 2012.

Saldívar, Dasso. García Márquez: Viaje a la semilla. Madrid: Alfaguara, 1997.

Sheridan, Guillermo y Pereira, Armando. "García Márquez en México (entrevista)". Revista de la Universidad de México 30/6 (1976).

Sierra, Germán. "El otoño del patriarca, epidemiología narrativa del estado despótico". Ortega, Julio, editor. Gaborio, artes de releer a García Márquez. México D.F: Jorale, 2003. 117-122.

Tobin, Patricia. "The Autumn of the Signifier: The Deconstructionist Moment of Garcia Marquez". Latin American Literary Review 13/25 (1985): 65-78.

Ugalde, Sharon Elizabeth Keefe. "Ironía en El otoño del patriarca". Inti 16-17 (19821983): 11- 26. <http://digitalcommons.providence.edu/inti/vol1/iss16/4/>.

Vargas Llosa, Mario. García Márquez. Historia de un deicidio. Barcelona: Barral, 1971. Zamora, Lois P. "The Myth of Apocalypse and Human Temporality in García Márquez's Cien años de soledad and El otoño del patriarca". Symposium 32/4 (1978): 341-356. 